\title{
The home environment and childhood obesity in low-income households: indirect effects via sleep duration and screen time
}

\author{
Bradley M Appelhans ${ }^{1 *}$, Stephanie L Fitzpatrick ${ }^{1}$, Hong Li ${ }^{1}$, Vernon Cail ${ }^{1}$, Molly E Waring ${ }^{2}$, Kristin L Schneider ${ }^{3}$, \\ Matthew C Whited ${ }^{4}$, Andrew M Busch ${ }^{5,6}$ and Sherry L Pagoto ${ }^{7}$
}

\begin{abstract}
Background: Childhood obesity disproportionally affects children from low-income households. With the aim of informing interventions, this study examined pathways through which the physical and social home environment may promote childhood overweight/obesity in low-income households.

Methods: Data on health behaviors and the home environment were collected at home visits in low-income, urban households with either only normal weight $(n=48)$ or predominantly overweight/obese $(n=55)$ children aged 6-13 years. Research staff conducted comprehensive, in-person audits of the foods, media, and sports equipment in each household. Anthropometric measurements were collected, and children's physical activity was assessed through accelerometry. Caregivers and children jointly reported on child sleep duration, screen time, and dietary intake of foods previously implicated in childhood obesity risk. Path analysis was used to test direct and indirect associations between the home environment and child weight status via the health behaviors assessed.

Results: Sleep duration was the only health behavior associated with child weight status (OR $=0.45,95 \%$ Cl: 0.27 , 0.77), with normal weight children sleeping 33.3 minutes/day longer on average than overweight/obese children. The best-fitting path model explained $26 \%$ of variance in child weight status, and included paths linking chaos in the home environment, lower caregiver screen time monitoring, inconsistent implementation of bedtime routines, and the presence of a television in children's bedrooms to childhood overweight/obesity through effects on screen time and sleep duration.

Conclusions: This study adds to the existing literature by identifying aspects of the home environment that influence childhood weight status via indirect effects on screen time and sleep duration in children from low-income households. Pediatric weight management interventions for low-income households may be improved by targeting aspects of the physical and social home environment associated with sleep.
\end{abstract}

Keywords: Childhood obesity, Socioeconomic status, Home environment, Sleep, Socioecologic model

\section{Background}

Childhood obesity disproportionally affects low-income children [1], which may contribute to socioeconomic disparities in obesity-related chronic diseases throughout the lifespan [2]. Socioecologic models attribute childhood obesity to intersecting social, economic, environmental, and psychobiologic drivers of energy intake and

\footnotetext{
* Correspondence: brad_appelhans@rush.edu

'Department of Preventive Medicine, Rush University Medical Center, 1700

W. Van Buren St., Suite 470, Chicago, IL 60612, USA

Full list of author information is available at the end of the article
}

expenditure [3]. Prior work based on this model has largely focused on neighborhood-level factors, such as local access to healthy and unhealthy foods, geographic density of fast food outlets and supermarkets, and venues for physical activity in relation to childhood obesity risk $[4,5]$. A few recent studies have highlighted the role of the home environment in childhood obesity, including both its physical features and social processes involving children and caregivers [6]. Physical home environments characterized by greater availability of unhealthy foods, fewer fruits and vegetables, more media equipment throughout 
the home and in the child's bedroom, and fewer sports/ recreational equipment items have been linked to childhood obesity risk [7-10]. Aspects of the social home environment, including caregiver modeling and policies towards healthy eating and physical activity, are also important influences $[11,12]$.

Very little research to date has examined childhood obesity risk factors in the home environments of lowincome households. In particular, little is known about aspects of the home environment that are associated with short sleep duration, which is highly prevalent among low-income minority youth [13] and has been consistently associated with weight gain and obesity status in prospective and cross-sectional studies [14-16]. This study compared the home environments of normal weight and overweight/obese children from low-income households. Consistent with socioecologic models of health and prior studies in non-disadvantaged populations, it was hypothesized that features of the physical and social home environment associated with healthy dietary intake, increased physical activity, reduced screen time, and longer sleep duration would discriminate between low-income households with exclusively normal weight children from those with predominantly overweight/obese children. An improved understanding of the features of the home environment most strongly associated with childhood obesity in low-income households could be leveraged to develop novel pediatric obesity interventions for this population. By comparing normal weight versus overweight/obese children within an entirely low-income population, this study reduced confounding by household income, and ensured that any therapeutic changes to the home environment suggested by the findings would be financially feasible for low-income families.

\section{Methods}

This manuscript reports the primary analyses from the Home Environment Comparison Study, a cross-sectional investigation of home environmental childhood obesity risk factors in low-income, urban households. Data were collected in Chicago, IL, USA during 2012-2013.

\section{Subjects}

Households were recruited through posted advertisements, pediatrician referrals, and word-of-mouth between May 2012 and March 2013. Eligible households were located in the city of Chicago, had at least one child between ages 6 and 13 years, reported a household income $\leq 250 \%$ of the Federal Poverty Threshold (FPT; $<\$ 57,625 /$ year for a 4-member household), and included an adult caregiver who made the majority of household food purchases and was willing to participate (index caregiver). Households also met criteria as cases or controls. In overweight/obese households (cases), at least $50 \%$ of children had a body mass index $\geq 85$ th percentile for their age and sex (consistent with the Centers for Disease Control and Prevention's definition [17]). In normal weight households (controls), all children ages 6 to 18 years had a body mass index $<85$ th percentile for their age and sex. Households in which $1 \%-49 \%$ of children ages 6 to 18 were overweight or obese were excluded to maximize observed group differences in home environments. Data collection focused on children ages 6-13 due to expectation that the diet, activity levels, and sleep patterns of children ages 14-18 may be less influenced by the physical and social home environment than younger children. To maximize observed group differences and reduce respondent burden in multiple-child households, data collection focused on one index child per household who had either the highest (overweight/obese weight households) or lowest (normal weight households) BMI percentile among children ages 6-13.

Exclusion criteria were selected to eliminate potential confounds and reduce barriers to data collection, including: 1) serious physical illness or developmental problem in any child age 6 to 13 (e.g., paraplegia, autism), 2) serious physical or psychiatric illness in a primary caregiver, 3) living in temporary or group housing or planning to move within 2 months, 4) lack of reliable telephone access, 5) lack of verbal English fluency, 6) and unwilling to meet with researchers in the home. Of 154 households who inquired about the study, 4 (3\%) declined screening, $22(14 \%)$ were eligible but did not enroll due to scheduling difficulties, and $25(16 \%)$ were excluded based on child weight status ( $\mathrm{n}=11)$, income $>250 \%$ of FPT $(\mathrm{n}=8)$, living outside Chicago $(n=4)$, living in temporary housing $(n=1)$, or because the primary household food shopper was unavailable to participate $(\mathrm{n}=1)$. The final sample included 103 households.

The study was conducted in accordance with the Declaration of Helsinki, and Rush University Medical Center's Institutional Review Board approved study procedures. Researchers obtained written documentation of informed consent and child assent. Caregivers were compensated $\$ 60.00$.

\section{Measures}

\section{Anthropometric measurements}

Index caregiver and index child height and weight were measured in light clothing without shoes using a scale and stadiometer (SECA models 876 and 213, Hamburg, Germany). Body mass index (BMI; $\mathrm{kg} / \mathrm{m}^{2}$ ) was calculated, and for children, BMI percentile for age and sex was determined.

\section{Physical activity}

The index child's engagement in moderate and vigorous physical activity was assessed through 7-day triaxial 
accelerometry (ActiGraph GT3X+; Actigraph LLC, Pensacola, $F L)$. Periods of no activity $\geq 20$ minutes were deemed nonwear times. To be included in analyses, subjects had to have at least 10 hours of valid wear time per day on a minimum of 3 weekdays and 1 weekend day [18]. Minutes of moderate and vigorous physical activity were calculated for each complete day of data using validated scoring criteria [19]. The weighted average of weekday (weight $=5 / 7$ or 0.714 ) and weekend (weight $=2 / 7$ or 0.286 ) physical activity was calculated.

\section{Screen time}

Items adapted from the Center for Disease Control and Prevention's 2011 State and Local Youth Risk Behavior Survey [20] were adapted to assess time spent watching television or movies, and playing video games or engaging in recreational computer use on typical school days and weekends. For ease of interpretation, analyses utilized the weighted average of weekday and weekend screen time based on the midpoints of each response category $(0,0.5$, $1.5,2.5$, and 3.5 hours per day).

\section{Index child dietary intake}

Caregivers and index children jointly reported on child consumption of specific categories of foods linked to obesity risk [21-23] during the past week on a 9-point scale from "Never" to " 5 or more times per day". Frequency of fruit and vegetable intake was assessed using four items and the response format from the National Cancer Institute's Fruit and Vegetable Screener [24], which included 100\% fruit juice, fruit, lettuce salad, and vegetables other than lettuce salad or fried potatoes. Intake of discretionary caloric beverages (regular soda, sports drinks, other sweetened beverages) and fast food during the past week were assessed with a subset of items from a validated screener [25]. Intake of seven categories of energy-dense snacks and desserts (chips/salty snack foods; candy; ice cream/frozen treats; cookies; cake/cupcakes; brownies/dessert bars/muffins; donuts/pastries) from a validated home food inventory [26] (described below) were assessed using the same response format. Total scores for fruit and vegetable intake, fast food and discretionary caloric beverage intake, and energy-dense snack intake were calculated.

\section{Sleep duration}

The Sleep Habits Survey [27] was used to assess usual total sleep time over the past two weeks. The Sleep Habits Survey has been validated against sleep actigraphy and sleep diaries in children [28]. Responses were provided by the index child with the assistance of caregivers, as caregivers tend to overestimate child sleep duration [29]. Usual sleep duration was calculated as the weighted average of weekday and weekend sleep durations in hours per day $(\mathrm{h} / \mathrm{d})$.

\section{Household characteristics and socioeconomic status}

Household income, household size, index caregiver education level, and child and caregiver gender and race/ ethnicity were assessed via self-report. Household income was quantified as a percentage of the Federal Poverty Threshold (FPT), which considers income relative to household size and composition.

\section{Home food environment}

A comprehensive, validated home food environment auditing tool was completed by research staff [26]. The tool assesses the presence and accessibility of 190 food items in 13 food group categories, including fruits (20 items), vegetables (26 items), and 71 calorie-dense indicator foods that contribute to an overall "obesogenic food availability score".

\section{Home activity and media environment}

Research staff completed a room-by-room audit using the Physical Activity and Media Inventory [9,30], which quantified the total number of media (5 items) and sports/recreational equipment (50 items) throughout the home. The presence of a television in the index child's bedroom was also recorded [10].

\section{Social home environment}

Items from the Family Nutrition \& Physical Activity Screening Tool assessed the frequency of family practices associated with childhood obesity [31]. The measure has 20 items scored from "Almost Never" (1) to "Almost Always" (4). Given our interest in specific caregiver behaviors, final path models utilized items and subscale scores for caregiver screen time monitoring (3 items; Cronbach $\alpha=0.67$ ) and consistent implementation of a bedtime routine ["almost always" $(\mathrm{n}=58)$ versus "almost never", "sometimes", or "usually" $(\mathrm{n}=45)]$.

\section{Chaotic home environment}

Index caregiver's perception of chaos and disorganization in the home environment was assessed using the Confusion, Hubbub, and Order Scale [32]. This measure has 15 true/false items that are summed to obtain total score (Cronbach $\alpha=0.81$ ).

\section{Data analysis}

Variable distributions were evaluated for normality and extreme values using skew and kurtosis indexes and normal quantile plots. Preliminary confirmatory factor analyses indicated that the three dietary intake variables (fruits and vegetables, discretionary caloric beverages and fast food, and energy-dense snacks) could not be reduced to one or two latent variables representing dietary intake. They were therefore treated as separate, observed variables. Logistic 
regression models tested associations between selected home environment variables and child weight status.

Our primary analyses were conducted in two stages. First, we sought to determine which proximal health behaviors were associated with child weight status in lowincome households. Associations between child weight status and six measured health behaviors (moderate and vigorous physical activity, screen time, sleep duration, and dietary intake of fruits and vegetables, discretionary caloric beverages and fast food, and energy-dense snacks) tested separately in logistic regression models with and without adjustment for index caregiver BMI.

In the second stage of analysis, path analysis was used to develop and test a theory-driven model linking aspects of the physical and social home environment to child weight status via effects on health behaviors associated with child weight status in the preceding analyses. Paths were added or removed from the model based on both theoretical considerations and model fit indices. Model chi-square with a $\mathrm{p}>.05$, comparative fit index $(\mathrm{CFI}) \geq .90$, and root mean square error of approximation (RMSEA) $\leq 0.05$ indicated good model fit [33]. Missing data were handled using full-information maximum likelihood.

Given the strong heritability of adiposity [34,35] and the possibility that caregivers may transmit risk for overweight/obesity to their children through effects on the home environment, effects of index caregiver BMI on child weight status were directly modeled in both stages of analysis. Child age, household income, and caregiver education were also considered as covariates. Mean- and variance-adjusted weighted least squares estimation was used because the dependent variable of child weight status was dichotomous, and this estimation technique is robust to non-normality in dependent variables [33]. Unstandardized path coefficients (b), standard errors, and p-values are reported, along with standardized path coefficients $(\beta)$ to facilitate interpretation of associations. Descriptive analyses and logistic regression models were conducted with Stata 11 (StataCorp LP, College Station, TX). Structural modeling was conducted with Mplus 7.11 (Muthén \& Muthén, Los Angeles, CA).

\section{Results}

The sample included 103 enrolled households (Table 1), $48(47 \%)$ of which were normal weight households and 55 (53\%) of which were overweight/obese households. Accelerometer data from 88 index children (85\% of total; $81 \%$ of normal weight households, $89 \%$ of overweight households) met $a$ priori criteria for valid wear time and were included in analyses. Complete data $(\mathrm{N}=103)$ were available for all other variables. No variable distribution had a skew index $>2.0$ or a kurtosis index $>7.0$, which are conservative guidelines for problematic non-normality in structural equation modeling [33]. Means, standard deviations, and zero-order correlations among study variables included in structural models are reported in Table 2.

In the first stage of our analyses (Table 3), sleep duration was the only measured health behavior that was significantly associated with child weight status (unadjusted $\mathrm{OR}=0.45,95 \% \mathrm{CI}: 0.27,0.77, \mathrm{p}=<.01)$. On average, normal weight children $(9.7 \mathrm{~h} / \mathrm{d})$ slept 33.3 minutes longer per night than overweight/obese index children $(9.2 \mathrm{~h} / \mathrm{d})$. The association was unchanged with adjustment for index caregiver BMI (adjusted OR $=0.45,95 \%$ CI: 0.26, $0.77, \mathrm{p}=<.01$ ). Higher index caregiver BMI was associated with greater odds of child overweight/obese status (adjusted $\mathrm{OR}=1.07,95 \% \mathrm{CI}: 1.02,1.13, \mathrm{p}=<.01$ ).

The second stage of analysis focused on modeling associations between the social and physical home environment and child weight status through mediating paths involving sleep duration. Variables included in the initial model were total media items in the home, the presence of a television in the index child's bedroom, screen time (as an influence on sleep duration), caregiver screen time monitoring, consistent implementation of a bedtime routine, perceived chaos and disorganization in the home environment, and several covariates (index caregiver BMI, child age, household income, index caregiver education). Total media items in the home was not associated with sleep duration or screen time and was removed from the model. The final path model (Table 4; Figure 1; model $\chi^{2}=5.11, \mathrm{p}=.95 ;$ CFI $=1.00 ;$ RMSEA $=0.00$ ) explained $26 \%$ of variance in weight status, and $23 \%$ of the variance in both sleep duration and screen time.

Finally, we examined associations between child weight status and several home environment variables that were not evaluated or retained in the stage two analyses. Home availability of fruits $(\mathrm{OR}=0.97,95 \% \mathrm{CI}: 0.87,1.09, \mathrm{p}=.62)$, vegetables $(\mathrm{OR}=0.93,95 \% \mathrm{CI}: 0.80,1.08, \mathrm{p}=.35)$, and obesity-promoting foods ( $\mathrm{OR}=1.02,95 \% \mathrm{CI}$ : $0.96,1.08$, $\mathrm{p}=.52)$ were not associated with child weight status. Similarly, the home availability of sports/recreational $(\mathrm{OR}=0.96,95 \% \mathrm{CI}: 0.89,1.03, \mathrm{p}=.25)$ and media $(\mathrm{OR}=$ $1.01,95 \%$ CI: $0.88,1.15, \mathrm{p}=.91$ ) equipment were not associated with child weight status.

\section{Discussion}

This is the first study to examine how objectively-measured features of the physical home environment and aspects of the social home environment are related to child weight status through their influences on health behaviors in an entirely low-income population. Specifically, our findings highlight the potential importance of targeting sleep in weight management interventions for low-income children by promoting consistent implementation of a bedtime routine, reducing chaos and disorganization in the home environment, and encouraging caregiver monitoring 
Table 1 Characteristics of enrolled households

\begin{tabular}{|c|c|c|c|c|}
\hline & $\begin{array}{c}\text { Total } \\
(\mathrm{N}=103)\end{array}$ & $\begin{array}{l}\text { Normal weight } \\
\quad(n=48)\end{array}$ & $\begin{array}{l}\text { Overweight } \\
(n=55)\end{array}$ & $p$-value ${ }^{a}$ \\
\hline \multicolumn{5}{|l|}{ Household } \\
\hline Household size [M (SD)] & $3.9(1.7)$ & $3.9(1.8)$ & $4.0(1.6)$ & .80 \\
\hline Income, \% FPT [M (SD)] ${ }^{\mathrm{b}}$ & $107.0(76.6)$ & $99.3(79.4)$ & $113.7(74.2)$ & .35 \\
\hline \multicolumn{5}{|l|}{ Index child } \\
\hline Age, years [M (SD)] & $10.0(2.5)$ & $9.8(2.5)$ & $10.1(2.5)$ & .58 \\
\hline BMI percentile [M (SD)] & $73.6(29.6)$ & $48.2(25.5)$ & $95.8(3.9)$ & $<.0001$ \\
\hline Female gender [n (\%)] & $54(52)$ & $23(48)$ & $31(56)$ & .39 \\
\hline Race/ethnicity [n (\%)] & & & & .88 \\
\hline Black/African-American & $79(77)$ & $37(77)$ & $42(76)$ & \\
\hline Hispanic/Latino & $18(18)$ & $9(19)$ & $9(16)$ & \\
\hline Multi-ethnic/Other & $3(3)$ & $1(2)$ & $2(4)$ & \\
\hline Non-Hispanic White/Caucasian & $2(2)$ & $1(2)$ & $1(2)$ & \\
\hline Asian & $1(1)$ & $0(0)$ & $1(2)$ & \\
\hline Receives subsidized school meals & $94(91.3)$ & $43(89.6)$ & $51(92.7)$ & .32 \\
\hline Fruit \& vegetables (range: 0-32) & $11.9(4.1)$ & $11.9(4.3)$ & $11.9(3.9)$ & .91 \\
\hline Fast food \& caloric beverages (range: $0-32$ ) & $9.2(3.5)$ & $8.8(3.4)$ & $9.5(3.5)$ & .30 \\
\hline Energy-dense snacks (range: 0-56) & $15.6(6.0)$ & $15.5(5.3)$ & $15.8(6.5)$ & .80 \\
\hline MVPA (mins/d; $n=88)$ & $48.4(22.2)$ & $49.2(18.6)$ & $47.7(24.9)$ & .76 \\
\hline Screen time $(\mathrm{h} / \mathrm{d})$ & $3.5(1.5)$ & $3.3(1.4)$ & $3.7(1.5)$ & .13 \\
\hline Sleep duration $(\mathrm{h} / \mathrm{d})$ & $9.5(0.9)$ & $9.7(0.9)$ & $9.2(0.9)$ & $<.01$ \\
\hline Caregiver screen time monitoring (range: $3-12$ ) & $7.7(2.1)$ & $8.2(2.0)$ & $7.2(2.1)$ & .01 \\
\hline Chaotic home environment (range: $0-15$ ) & $3.2(3.1)$ & $2.7(2.9)$ & $3.6(3.3)$ & .13 \\
\hline \multicolumn{5}{|l|}{ Index caregiver } \\
\hline Age, years [M (SD)] & $36.5(7.4)$ & $36.2(7.2)$ & $36.7(7.6)$ & 0.72 \\
\hline $\mathrm{BMI}, \mathrm{kg} / \mathrm{m}^{2}[\mathrm{M}(\mathrm{SD})]$ & $33.5(9.6)$ & $30.5(9.3)$ & $36.0(9.3)$ & $<.01$ \\
\hline Female gender [n (\%)] & $97(94)$ & $44(92)$ & $53(96)$ & .31 \\
\hline Race/ethnicity [n (\%)] & & & & 0.83 \\
\hline Black/African-American & $79(77)$ & $37(77)$ & $42(76)$ & \\
\hline Hispanic/Latino & $17(17)$ & $8(17)$ & $9(16.4)$ & \\
\hline Multi-ethnic/Other & $1(1)$ & $0(0)$ & $1(2)$ & \\
\hline Non-Hispanic White/Caucasian & $6(6)$ & $3(6)$ & $3(6)$ & \\
\hline Asian & $0(0)$ & $0(0)$ & $0(0)$ & \\
\hline Education [n (\%)] & & & & .14 \\
\hline High school or lower & $25(24)$ & $15(31)$ & $10(18)$ & \\
\hline Some college/technical school & $64(62)$ & $25(52)$ & $39(71)$ & \\
\hline 4-year degree or higher & $14(14)$ & $8(17)$ & $6(11)$ & \\
\hline
\end{tabular}

FPT, Federal Poverty Threshold; BMI, body mass index; MVPA, moderate and vigorous physical activity.

${ }^{a}$ For tests of group differences through t-test or chi-square test.

${ }^{b}$ FPTs are set by the U.S. Census Bureau based on annual household income and the number of related adults and children in the household.

of screen time. Our data also support removing televisions from children's bedrooms, which is commonly addressed in pediatric weight management interventions. In contrast to prior studies [9], the availability of sports/recreational equipment in the home was not associated with weight status. If this result reflects a true lack of association in the population, rather than insufficient statistical power, it would suggest that increasing access to sports/recreational equipment is unlikely to promote weight loss in lowincome children, even though these items are less abundant in low-income households than higher-income households [36]. 
Table 2 Correlations among continuous variables included in path analyses $(\mathbb{N}=103$ unless otherwise noted)

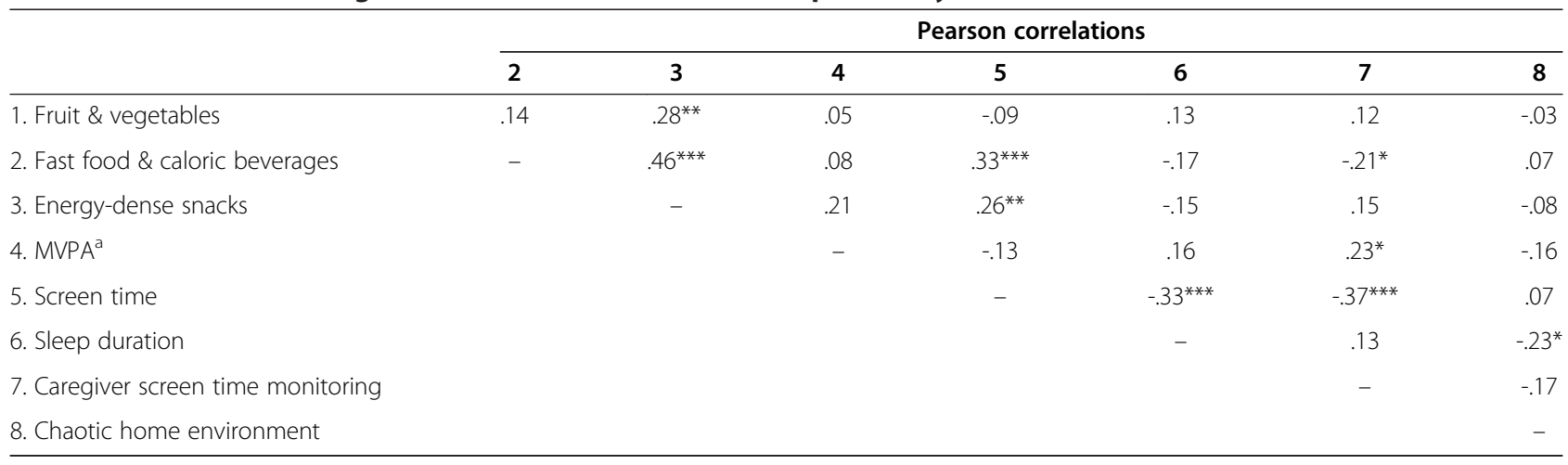

${ }^{*} \mathrm{p}<.05,{ }^{* *} \mathrm{p}<.01,{ }^{* * *} \mathrm{p}<.001$.

MVPA, daily minutes of moderate and vigorous physical activity.

${ }^{\text {a }} \mathrm{N}=88$ for this variable.

Several associations observed in our sample of lowincome children converge with prior studies in different populations. A recent Australian study reported that a longitudinal association between short sleep duration at ages 4-5 years and higher adiposity at ages 8-9 years was partially mediated by increases in television viewing time in the intervening years [37]. Another study involving third through fifth graders in Iowa and Minnesota, USA found that parental monitoring of media use was associated with longer sleep duration through indirect effects on screen time [38]. The current findings indicate that sleep duration and screen time are important influences on weight status in children from low-income households (and are not simply artifacts of confounding by socioeconomic status), and also provides new information on the features of the home environment that may influence these behaviors in this population.

Very few published pediatric weight management interventions include a strong focus on modifying the home environment. One exception is a recent trial involving predominantly low-income children ages $2-5$ years, which reported that a 6-month, home-based, health education intervention focused on adopting healthy family routines led to longer sleep duration, decreased television viewing, and a small but positive effect on BMI [39]. Our group is currently pilot testing a home-based, parent-only weight management intervention for low-income children ages 6-13 years that targets children's sleep, dietary intake, and physical activity through guided modification of the home environment and parent skills training.

Traditional childhood obesity risk factors such as physical activity, screen time, and intake of discretionary caloric beverages and fast food, energy-dense snacks, and fruits and vegetables, were not directly related to weight status in this study. Reduced variability in these behaviors may account for the lack of observed associations, as lowincome children's physical activity and diet may be constrained by school physical education policies, reliance on subsidized school meals (91\% of index children received free/reduced school meals), local access to healthy food and physical activity venues, and socioeconomic influences on household food choices. The presence of such constraints may result in sleep accounting for a larger proportion of variance in weight status in this population.

Table 3 Associations between health behaviors and odds of child overweight/obese weight status, with and without adjustment for index caregiver BMI $(N=103)$

\begin{tabular}{|c|c|c|c|c|c|c|}
\hline & \multicolumn{3}{|c|}{ Unadjusted } & \multicolumn{3}{|c|}{ Adjusted for caregiver BMI } \\
\hline & OR & $95 \% \mathrm{Cl}$ & $p$-value & OR & $95 \% \mathrm{Cl}$ & $p$-value \\
\hline Fruit and vegetable intake ${ }^{a, b}$ & 1.01 & $0.91,1.11$ & .91 & 1.03 & $0.93,1.14$ & .59 \\
\hline Caloric beverages and fast food ${ }^{a, b}$ & 1.06 & $0.95,1.20$ & .30 & 1.07 & $0.95,1.21$ & .27 \\
\hline Energy-dense snacks ${ }^{\mathrm{a}, \mathrm{c}}$ & 1.01 & $0.94,1.08$ & .80 & 1.02 & $0.95,1.09$ & .55 \\
\hline Screen time $(\mathrm{h} / \mathrm{d})$ & 1.23 & $0.94,1.61$ & .14 & 1.17 & $0.89,1.57$ & .26 \\
\hline MVPA (mins/d) ${ }^{d}$ & 1.00 & $0.98,1.02$ & .76 & 1.00 & $0.98,1.02$ & .92 \\
\hline Sleep duration $(\mathrm{h} / \mathrm{d})$ & 0.45 & $0.27,0.77$ & $<.01$ & 0.45 & $0.26,0.77$ & $<.01$ \\
\hline
\end{tabular}

MVPA, daily minutes of moderate and vigorous physical activity.

${ }^{a}$ Measured on an ordinal scale reflecting frequency of intake in the past 7 days.

${ }^{\mathrm{b}}$ Possible scores ranged from $0-32$.

'Possible scores ranged from $0-56$.

${ }^{\mathrm{d}} \mathrm{N}=88$ for this variable. 
Table 4 Unstandardized (b) and standardized $(\beta)$ path coefficients for final model ${ }^{a}$ of home environment variables, sleep duration, and child overweight/obese status $(\mathrm{N}=103)$

\begin{tabular}{|c|c|c|c|c|}
\hline & b & SE & $\beta$ & $p$-value \\
\hline \multicolumn{5}{|l|}{ Direct effects on weight status } \\
\hline Index caregiver BMI & .04 & .01 & .34 & $<.01$ \\
\hline Sleep duration & -.44 & .11 & -.37 & $<.001$ \\
\hline \multicolumn{5}{|l|}{ Direct effects on sleep duration } \\
\hline Index child age & -.07 & .04 & -.18 & .08 \\
\hline CHAOS & -.06 & .03 & -.19 & .03 \\
\hline Bedtime routine & .34 & .20 & -.19 & .08 \\
\hline Screen time & -.17 & .05 & -.28 & $<.001$ \\
\hline \multicolumn{5}{|l|}{ Direct effect on screen time } \\
\hline TV in bedroom & .85 & .33 & .26 & $<.01$ \\
\hline CSM & -.31 & .08 & -.45 & $<.001$ \\
\hline Index child age & .12 & .06 & .20 & .04 \\
\hline \multicolumn{5}{|l|}{ Indirect effects } \\
\hline CHAOS $\rightarrow$ Sleep $\rightarrow$ Weight status & .03 & .01 & .07 & .06 \\
\hline Bedtime routine $\rightarrow$ Sleep $\rightarrow$ Weight status & -.15 & .09 & -.07 & .10 \\
\hline Screen time $\rightarrow$ Sleep $\rightarrow$ Weight status & .08 & .03 & .10 & $<.01$ \\
\hline CSM $\rightarrow$ Screen time $\rightarrow$ Sleep $\rightarrow$ Weight status & -.02 & .01 & -.05 & .02 \\
\hline TV $\rightarrow$ Screen time $\rightarrow$ Sleep $\rightarrow$ Weight status & .07 & .03 & .03 & .06 \\
\hline
\end{tabular}

BMI, body mass index.

CSM, caregiver screen time monitoring.

CHAOS, chaos and disorganization in the home environment.

TV, TV present in index child's bedroom.

${ }^{\mathrm{a}}$ Model $\chi^{2}=5.11, \mathrm{p}=.95 ; \mathrm{CFI}=1.00$; RMSEA $=0.00,90 \% \mathrm{Cl}: 0.00,0.00$.

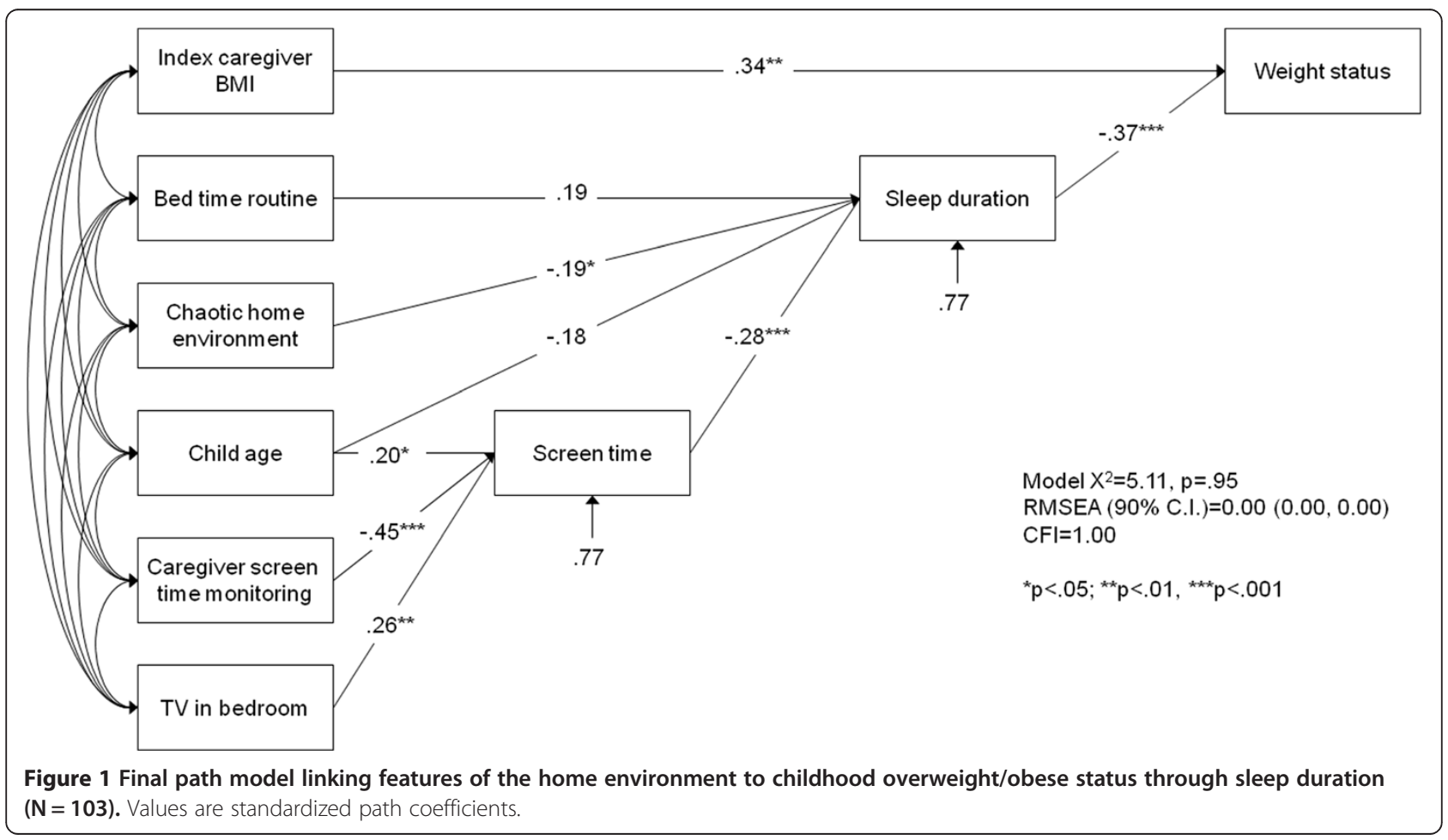


Disparities in childhood obesity have been attributed to differences in diet, screen time, and physical activity in studies that compare high- and low-income subjects, but these factors have been less consistently associated with weight status in other studies that include only low-income subjects [40]. The current findings suggest that the health behaviors that underlie socioeconomic disparities in childhood obesity differ from those associated with obesity within an entirely low-income population.

A major strength of this study was the use of objective audit-based measures of the physical home environment, which eliminates the reporting bias that can occur with self-report measures. The use of in-home data collection also eliminated lack of transportation or childcare as barriers to participation, which is important in low-income populations. The study also examined childhood obesity risk factors exclusively among lowincome households eliminates income as a confounding factor and enables the development of home-based interventions that are compatible with the resources of lowincome households.

This study also had several limitations. The sample was composed primarily of African-American households in Chicago, and a different pattern of findings may be observed in other populations. The use of a convenience sampling methods (e.g., advertisements, pediatrician referrals) further limits generalizability to the broader population. Our eligibility criteria focused on household income as the sole determinant of socioeconomic position. Though our sample was $98 \%$ ethnic minority and caregivers had a low-level of educational attainment, confounding by other aspects of socioeconomic position such as occupational class, wealth, and acculturation were not addressed. The sample size was small, which limited statistical power, precluded moderator analyses, and reduced the stability of path coefficients. As a result, non-significant associations should not be interpreted as a definitive indication that no such association exists in the population. Sleep duration was assessed with a validated self-report measure of bedtimes and waketimes, which tends to overestimate sleep duration relative to sleep actigraphy [28]. We also did not assess sleep disordered breathing, which could represent a reverse causal pathway in which weight status leads to short sleep duration. The lack of observed associations with dietary intake may stem from our focus on the frequency of intake of specific food categories. Our measures did not capture portion size, overall energy intake, or diet quality. The cross-sectional nature of the study cannot assess causality, and prospective studies examining the roles of the home environment, screen time, and sleep on obesity in low-income children are warranted. Finally, an inherent limitation of path analysis is that it can only compare alternative theoretical models based on their relative fit with observed data, and decisions about which models to test require some subjective judgment on the part of the investigators [33].

\section{Conclusion}

The main finding from this study is that several aspects of the physical and social home environment were related to childhood weight status via their indirect associations involving sleep duration and screen time. Interventions that explicitly target these features of the home environment could augment pediatric weight management interventions in low-income populations.

\section{Abbreviations}

BMI: Body mass index; CFI: Comparative fit index; Cl: Confidence interval; FPT: Federal poverty threshold; OR: Odds ratio; RMSEA: Root mean square error of approximation.

\section{Competing interests}

The authors declare that they have no competing interests.

\section{Authors' contributions}

BMA conceptualized and designed the study and drafted the initial manuscript. SLF helped develop the analysis plan. HL conducted statistical analyses. VC helped design data collection procedures, recruited subjects, and collected data. MEW, KLS, MCW, AMB, and SLP contributed to the conceptualization and interpretation of analyses. All authors reviewed, revised, and approved the final manuscript.

\section{Acknowledgements}

This work was supported by grant \#225076 from the American Cancer Society, Illinois Division, Inc. to BMA. The project was also supported by $\mathrm{NIH}$ Grant P5OHL105189. The sponsor had no role in study design; in the collection, analysis, or interpretation of data; in the writing of the report; or in the decision to submit the manuscript for publication. Support for MEW provided by NIH grants KL2TR000160 and 1U01HL105268. Salary support for AMB was provided by NIH grant K23HL107391. Salary support for MCW provided by NIH grant 5K23HL109620.

\section{Author details}

${ }^{1}$ Department of Preventive Medicine, Rush University Medical Center, 1700 W. Van Buren St., Suite 470, Chicago, IL 60612, USA. ${ }^{2}$ Department of Quantitative Health Sciences, University of Massachusetts Medical School, Worcester, MA, USA. ${ }^{3}$ Department of Psychology, Rosalind Franklin University, North Chicago, IL, USA. ${ }^{4}$ Department of Psychology, East Carolina University, Greenville, NC, USA. ${ }^{5}$ Department of Psychiatry and Human Behavior, Brown University, Providence, RI, USA. ${ }^{6}$ The Miriam Hospital, Providence, RI, USA.

${ }^{7}$ Division of Preventive and Behavioral Medicine in the Department of Medicine, University of Massachusetts Medical School, Worcester, MA, USA.

Received: 25 June 2014 Accepted: 21 October 2014

Published: 9 November 2014

\section{References}

1. Ogden $C L$, Lamb MM, Carroll MD, Flegal KM: Obesity and socioeconomic status in children and adolescents: United States, 2005-2008. NCHS Data Brief 2010, 51:1-8.

2. Senese LC, Almeida ND, Fath AK, Smith BT, Loucks EB: Associations between childhood socioeconomic position and adulthood obesity. Epidemiol Rev 2009, 31:21-51

3. Booth SL, Sallis JF, Ritenbaugh C, Hill JO, Birch LL, Frank LD, Glanz K, Himmelgreen DA, Mudd M, Popkin BM, Rickard KA, St Jeor S, Hays NP: Environmental and societal factors affect food choice and physical activity: rationale, influences, and leverage points. Nutr Rev 2001, 59(3 Pt 2):S21-S39.

4. Larson NI, Story MT, Nelson MC: Neighborhood environments: disparities in access to healthy foods in the U.S. Am J Prev Med 2009, 36:74-81.

5. Galvez MP, McGovern K, Knuff C, Resnick S, Brenner B, Teitelbaum SL, Wolff MS: Associations between neighborhood resources and physical activity in inner-city minority children. Acad Ped 2013, 13:20-26. 
6. Davison KK, Birch LL: Childhood overweight: a contextual model and recommendations for future research. Obes Rev 2001, 2:159-171.

7. Campbell KJ, Crawford DA, Salmon J, Carver A, Garnett SP, Baur LA: Associations between the home food environment and obesity-promoting eating behaviors in adolescence. Obesity 2007, 15:719-730.

8. Vereecken C, Haerens L, De Bourdeaudhuij I, Maes L: The relationship between children's home food environment and dietary patterns in childhood and adolescence. Public Health Nutr 2010, 13(10A):1729-1735.

9. Sirard JR, Laska MN, Patnode CD, Farbakhsh K, Lytle LA: Adolescent physical activity and screen time: associations with the physical home environment. Int J Behav Nutr Phys Act 2010, 7:82.

10. Dennison BA, Erb TA, Jenkins PL: Television viewing and television in bedroom associated with overweight risk among low-income preschool children. Pediatrics 2002, 109:1028-1035.

11. Gubbels JS, Kremers SP, Stafleu A, de Vries SI, Goldbohm RA, Dagnelie PC, de Vries NK, van Buuren S, Thijs C: Association between parenting practices and children's dietary intake, activity behavior and development of body mass index: the KOALA Birth Cohort Study. Int J Behav Nutr Phys Act 2011, 8:18.

12. Pearson N, Timperio A, Salmon J, Crawford D, Biddle SJ: Family influences on children's physical activity and fruit and vegetable consumption. Int $J$ Behav Nutr Phys Act 2009, 6:34.

13. Wong $\mathrm{WW}$, Ortiz $\mathrm{CL}$, Lathan $\mathrm{D}$, Moore $\mathrm{LA}$, Konzelmann $\mathrm{KL}$, Adolph $\mathrm{AL}$, Smith EO, Butte NF: Sleep duration of underserved minority children in a cross-sectional study. BMC Public Health 2013, 13:648.

14. Seegers V, Petit D, Falissard B, Vitaro F, Tremblay RE, Montplaisir J, Touchette E: Short sleep duration and body mass index: a prospective longitudinal study in preadolescence. Am J Epidemiol 2011, 173:621-629.

15. Cappuccio FP, Taggart FM, Kandala NB, Currie A, Peile E, Stranges S, Miller MA: Meta-analysis of short sleep duration and obesity in children and adults. Sleep 2008, 31:619-626

16. Chen $X$, Beydoun MA, Wang $Y$ : Is sleep duration associated with childhood obesity? A systematic review and meta-analysis. Obesity 2008 16:265-274.

17. Ogden $\mathrm{CL}$, Flegal KM: Changes in terminology for childhood overweight and obesity. Natl Health Stat Report 2010, 25:1-5.

18. Trost SG, Mclver KL, Pate RR: Conducting accelerometer-based activity assessments in field-based research. Med Sci Sports Exerc 2005, 37(11 Suppl):S531-S543

19. Evenson KR, Catellier DJ, Gill K, Ondrak KS, McMurray RG: Calibration of two objective measures of physical activity for children. J Sports Sci 2008, 26:1557-1565.

20. Centers for Disease C, Prevention, Brener ND, Kann L, Shanklin S, Kinchen S, Eaton DK, Hawkins J, Flint KH: Methodology of the youth risk behavior surveillance system-2013. MMWR 2013, 62(RR-1):1-20,

21. Ledoux TA, Hingle MD, Baranowski T: Relationship of fruit and vegetable intake with adiposity: a systematic review. Obes Rev 2011, 12:e143-e150.

22. Malik VS, Schulze MB, Hu FB: Intake of sugar-sweetened beverages and weight gain: a systematic review. Am J Clin Nutr 2006, 84:274-288.

23. Rosenheck R: Fast food consumption and increased caloric intake: a systematic review of a trajectory towards weight gain and obesity risk. Obes Rev 2008, 9:535-547.

24. Thompson FE, Subar AF, Smith AF, Midthune D, Radimer KL, Kahle LL, Kipnis V: Fruit and vegetable assessment: performance of 2 new short instruments and a food frequency questionnaire. J Am Diet Assoc 2002, 102:1764-1772.

25. Nelson MC, Lytle LA: Development and evaluation of a brief screener to estimate fast-food and beverage consumption among adolescents. J Am Diet Assoc 2009, 109:730-734.

26. Fulkerson JA, Nelson MC, Lytle L, Moe S, Heitzler C, Pasch KE: The validation of a home food inventory. Int J Behav Nutr Phys Act 2008, 5:55.

27. Wolfson AR, Carskadon MA: Sleep schedules and daytime functioning in adolescents. Child Dev 1998, 69:875-887.

28. Wolfson AR, Carskadon MA, Acebo C, Seifer R, Fallone G, Labyak SE, Martin JL: Evidence for the validity of a sleep habits survey for adolescents. Sleep 2003, 26:213-216.

29. Short MA, Gradisar M, Lack LC, Wright HR, Chatburn A: Estimating adolescent sleep patterns: parent reports versus adolescent self-report surveys, sleep diaries, and actigraphy. Nat Sci Sleep 2013, 5:23-26.

30. Sirard JR, Nelson MC, Pereira MA, Lytle LA: Validity and reliability of a home environment inventory for physical activity and media equipment. Int J Behav Nutr Phys Act 2008, 5:24.
31. Ihmels MA, Welk GJ, Eisenmann JC, Nusser SM: Development and preliminary validation of a Family Nutrition and Physical Activity (FNPA) screening tool. Int J Behav Nutr Phys Act 2009, 6:14

32. Matheny AP, Washs TD, Ludwig JL, Phillips K: Bringing order out of chaos: psychometric characteristics of the confusion, hubbub, and order scale. J Appl Dev Psychol 1995, 16:429-444.

33. Kline RB: Principles and Practice of Structural Equation Modeling. 3rd edition. New York: The Guilford Press; 2011.

34. Schousboe K, Visscher PM, Erbas B, Kyvik KO, Hopper JL, Henriksen JE, Heitmann BL, Sørensen TI: Twin study of genetic and environmental influences on adult body size, shape, and composition. Int J Obes Relat Metab Dis 2004, 28:39-48.

35. Stunkard AJ, Foch TT, Hrubec Z: A twin study of human obesity. JAMA 1986, 256:51-54

36. Tandon PS, Zhou C, Sallis JF, Cain KL, Frank LD, Saelens BE: Home environment relationships with children's physical activity, sedentary time, and screen time by socioeconomic status. Int J Behav Nutr Phys Act 2012, 9:88.

37. Magee C, Caputi P, Iverson D: Lack of sleep could increase obesity in children and too much television could be partly to blame. Acta Paediatr 2014, 103:e27-e31.

38. Gentile DA, Reimer RA, Nathanson Al, Walsh DA, Eisenmann JC: Protective effects of parental monitoring of children's media use: a prospective study. JAMA Pediatr 2014, 168:479-484.

39. Haines J, McDonald J, O'Brien A, Sherry B, Bottino CJ, Schmidt ME, Taveras EM: Healthy habits, happy homes: randomized trial to improve household routines for obesity prevention among preschool-aged children. JAMA Pediatr 2013, 167:1072-1079.

40. Wang $Y$, Liang H, Tussing L, Braunschweig C, Caballero B, Flay B: Obesity and related risk factors among low socio-economic status minority students in Chicago. Public Health Nutr 2007, 10:927-938.

doi:10.1186/1471-2458-14-1160

Cite this article as: Appelhans et al:: The home environment and childhood obesity in low-income households: indirect effects via sleep duration and screen time. BMC Public Health 2014 14:1160.

\section{Submit your next manuscript to BioMed Central and take full advantage of:}

- Convenient online submission

- Thorough peer review

- No space constraints or color figure charges

- Immediate publication on acceptance

- Inclusion in PubMed, CAS, Scopus and Google Scholar

- Research which is freely available for redistribution

Submit your manuscript at www.biomedcentral.com/submit
C Biomed Central 